\title{
The international spillover effects of pension reform
}

\author{
Yvonne Adema • Lex Meijdam • \\ Harrie A.A. Verbon
}

Published online: 13 June 2008

(C) The Author(s) 2008. This article is published with open access at Springerlink.com

\begin{abstract}
This paper explores how pension reforms in countries with PAYG schemes affect countries with funded systems. We use a two-country two-period overlappinggenerations model, where the countries only differ in their pension systems. We distinguish between the case where a reform potentially leads to a Pareto improvement in the PAYG country, and where this is impossible. In the latter case, the funded country shares both in the costs and the benefits of the reform. However, if a Paretoimproving pension reform is feasible in the PAYG country, a Pareto improvement in the funded country is not guaranteed.
\end{abstract}

Keywords International spillover effects $\cdot$ Pension reform

JEL Classification F21 $\cdot$ F41 $\cdot$ F47 $\cdot$ H55 $\cdot$ H63

\section{Introduction}

In many developed countries, aging has led to a debate on reforming unfunded payas-you-go (PAYG) social-security systems. One of the most discussed reform proposals is to switch to a more funded pension system where people save for their own pensions, and realize a higher expected rate of return on their contributions (see, for

Y. Adema $(\varangle) \cdot$ L. Meijdam · H.A.A. Verbon

CentER, Netspar, and Department of Economics, Tilburg University, P.O. Box 90153, 5000 LE

Tilburg, The Netherlands

e-mail: y.adema@uvt.nl

L. Meijdam

e-mail: a.c.meijdam@uvt.nl

H.A.A. Verbon

e-mail: h.a.a.verbon@uvt.nl 
example, Feldstein 2005 and Bovenberg 2003). Many countries with PAYG-financed pension schemes actually (are planning to) implement such pension reforms. In a multicountry world with integrated capital markets, such a switch to funding will engender spillover effects to other countries. The aim of this paper is to look at these international spillover effects of pension reform. More specifically, we will analyze how countries with funded pension systems are affected when countries with PAYG pension schemes reform their pension system.

Some papers (e.g., Fehr et al. 2005; Börsch-Supan et al. 2006 and INGENUE 2001) that address pension reform issues in an open-economy framework develop large multi-country overlapping-generation models to study the effects of pension reform. These large-scale general equilibrium models are particularly useful in case one wants to obtain reliable forecasts on several key economic variables. An important drawback of these models is, however, that analytical solutions are not feasible and the underlying mechanisms of the results are not clear. We use a simple twocountry two-period overlapping-generations model with an integrated capital market, where one country has a PAYG pension system and the other country has a fully funded retirement scheme. By keeping the model this simple, we are able to derive an analytical solution for the transition path of the common capital-labor ratio, and to derive the spillover effects of pension reform. ${ }^{1}$

In analyzing the effects of a pension reform in the PAYG country, we first assume that collecting contributions in the PAYG country does not involve any distortions. It is well known that in such a case, the PAYG system is Pareto efficient, see Verbon (1989) and Breyer (1989). ${ }^{2}$ This means that if some generations are allowed to gain from the conversion policy, it is unavoidable that other generations incur a loss. So, in the reforming country, a choice has to be made which generations are allowed to gain from the reform and which not. In general, future generations in the PAYG country gain if the reform implies an increase in the capital-labor ratio, the reason being that the PAYG country is a borrower on the common capital market and, therefore, gains both from the lower interest rate that goes along with an increase in the capital-labor ratio and from the higher wages. As the funded country is a lender on the common capital market, the increasing capital-labor ratio does not necessarily imply welfare gains for future generations in the funded country. However, we can show that under plausible parameter configurations the reforming country's choice spills positively over to the funded country in a common capital market. In particular, if the reforming country decides that future generations will gain from the reform, future generations in the non-reforming country will gain as well. But just like in the reforming country, this long-run welfare gain may come at the cost of lower utility in the short run as, due to the rising capital-labor ratio, the increase in wages for initial generations is relatively small compared to the decrease in the interest rate.

\footnotetext{
${ }^{1}$ Other papers that study the open economy aspects of pension schemes using smaller models are, for example, Pestieau et al. (2006), who consider the issue of the optimal PAYG scheme in a setting where the number of symmetric countries changes, and Bräuninger (1999), who focuses on the optimal degree of social security funding in a two-country framework. We, however, abstract from optimality issues.

${ }^{2}$ Actually, we already know from the classic papers of Samuelson (1958) and Gale (1973) that if the economy is dynamically efficient no intergenerational redistribution can be Pareto improving.
} 
We then proceed by assuming excess burdens in tax collection. It has been shown that in that case a Pareto-improving pension reform is possible in a closed economy (Homburg 1990). The idea is that if the contribution rate is decreased net welfare gains result which make it possible to compensate the elderly for the loss of their benefits. When a Pareto-improving policy is implemented in our two-country world, the long-run gains in the PAYG country are again transferred to the funded country. However, although in the PAYG country, the policy is carefully shaped such that no generation loses in both the short run and the long run, in the funded country some generations might lose in the short run. The reason for this is that in the open capital market the additional savings that emerge during the conversion policy in the PAYG country will depress the interest rate, which especially harms the generations that are alive in the funded country when the PAYG country starts the conversion policy. As these generations do not, or do not fully, receive the gains that result from increasing wages, they are not compensated for the negative utility effects of the lower interest rate.

In principle, replacing a PAYG-financed public pension scheme by a funded pension scheme implies that pension claims of the current retired are no longer honored. In this respect, the switch to funding is comparable to imposing a lump-sum tax on the current old generations in order to decrease the size of the government debt. Exactly the reverse of this policy scenario, i.e., granting a lump-sum tax decrease to older generations financed by increasing the government debt was already analyzed by Diamond (1965) in a one-country model and by Persson (1985) in a two-country model. ${ }^{3}$ Based on this similarity, our paper can be seen as a merger between the pension reform literature, where international spillover effects received relatively little attention, and the literature on the effects of government debt, where the international externalities did not remain unnoticed. Some of our results are closely linked to the conclusions of Persson (1985). For example, the spillover effects of reforming a Pareto-efficient PAYG scheme without compensating the initial generation of elderly are qualitatively the same as those of a decrease in government debt: both lead to a decrease in the interest rate on the international capital market. However, other reform scenarios that we discuss, and especially the Pareto-improving reform, do not fit into Persson's set up and, therefore, extend his analysis.

Steigum and Raffelhüschen (1994) find in a calibrated two-country model, with North America and the rest of the OECD taken as the two countries of interest, that the welfare effects of debt changes in one country are relatively minor. The reason for this result is that the change in debt in one country is small compared to the total capital stock in the common capital market. ${ }^{4}$ We allow for differences in the

\footnotetext{
${ }^{3}$ Other papers that analyze public debt in an international setting are, for example, Fried and Howitt (1988) and Homburg and Richter (1993). These papers use models based on assumptions that essentially differ from ours: The former abstracts from capital accumulation and examines the effect of government debt on capital gains and losses; the latter analyzes the problem of harmonizing debt and public pension schemes when labor is perfectly mobile.

${ }^{4}$ Another reason is that Steigum and Raffelhüschen (1994) assume endogenous labor supply. In our setting, this would imply that a tax decrease, due to pension reform, stimulates labor supply which dampens the savings, and thereby the general-equilibrium effect of the reform. Empirical estimates of labor-supply elasticities for the principal earner of a household, however, generate relatively low values, see Blundell and MaCurdy (1999) for an overview.
} 
Table 1 Composition of retirement incomes in 2003 (\%)

\begin{tabular}{llll}
\hline & First pillar & Second pillar & Third pillar \\
\hline Greece & 98 & 1.5 & 0.5 \\
France & 97 & 1.5 & 1.5 \\
Spain & 97 & 1.5 & 1.5 \\
Italy & 96 & 2 & 2 \\
Austria & 95 & 3 & 2 \\
Germany & 94 & 4 & 2 \\
Denmark & 76 & 20 & 4 \\
Sweden & 75 & 20 & 5 \\
Switzerland & 72 & 26 & 2 \\
Netherlands & 56 & 37 & 7 \\
\hline
\end{tabular}

Source: Boeri et al. (2006)

size of the two countries by introducing a parameter that measures the relative size of the funded country. The analysis presented in this paper can then be applied to the case where a group of countries shifts to more funded pensions, while a small number of countries do not reform their pension system. An interesting example of this can be observed in the EU where, broadly speaking, two groups of countries can be distinguished: a large group of countries with extensive PAYG schemes, but almost no funded pensions, and a much smaller group of countries having sizeable funded pensions (see Table 1). Many of the countries in the first group are discussing (or have already started) a transition to more funded pensions. This reform will lead to sizeable changes in the capital stock in the long run, irrespective of whether the reform is gradually implemented or not and, therefore, have important consequences for the countries that already have more elaborate funded pension schemes, especially because this group of countries is small compared to the group of reforming countries.

The rest of the paper is organized as follows. Section 2 presents the benchmark model and shows how the pension reform is modeled. In Sect. 3, we analyze different types of reform scenarios under the assumption that the PAYG scheme is Pareto efficient, while Sect. 4 considers the effects in case the reform is Pareto improving in the PAYG country. In these sections, we illustrate the effects of the reform by numerical simulation examples using Cobb-Douglas specifications. Analytical derivations of the results using more general utility and production functions are presented in the Appendix. The paper winds up with a concluding section.

\section{The model}

We will use a two-period overlapping-generations model of an open economy. Following Buiter (1981) and Persson (1985), the world consists of two countries, country $P$ and country $F$. Countries differ in the way the pensions are financed. Country $P$ uses a pay-as-you-go (PAYG) system and country $F$ has a fully funded retire- 
ment scheme. We assume a constant population size ${ }^{5}$ and dynamic efficiency in both countries. Countries may, however, differ in population size. In this way, we allow for scale differences between the two countries. When we define $\frac{L^{F}}{L^{P}}=v$ and normalize $L^{P}$ to 1 , then $v$ tells us the relative size of $L^{F}$. The countries are identical in all other respects.

\subsection{Production}

Production per young individual is described by a standard neoclassical constantreturns-to-scale production function, $f\left(k_{t}^{i}\right)$, where $k_{t}^{i}$ stands for the amount of capital per young individual in period $t$, in country $i, i=P, F$. Perfect competition among producers gives the usual equilibrium conditions, $r_{t}^{i}=f^{\prime}\left(k_{t}^{i}\right)-\delta$ and $w_{t}^{i}=f\left(k_{t}^{i}\right)-k_{t}^{i} f^{\prime}\left(k_{t}^{i}\right)$, where $r_{t}^{i}$ is the interest rate, $w_{t}^{i}$ denotes the real wage, and $\delta$ is the depreciation rate of capital. There is perfect capital mobility between the two countries, but labor is immobile. Since capital can freely move across countries, the interest rates will be equalized, i.e., $r_{t}^{P}=r_{t}^{F}=r_{t}, \forall t$. And because both countries are endowed with the same production technology, we have $k_{t}^{P}=k_{t}^{F}=k_{t}$, and consequently, $w_{t}^{P}=w_{t}^{F}=w_{t}$.

\subsection{Modelling pensions and reform}

Initially, the government in country $P$ runs a balanced PAYG pension system, that is, taxes of the young $\left(\tau_{t}^{P}\right)$ are used to finance the pension benefits of the elderly $\left(z_{t}^{P}\right)$. As explained in the Introduction, we distinguish between the case where the PAYG system is efficient and the case where the PAYG scheme leads to distortions in the economy. In the latter case, the PAYG tax implies an excess burden. This has been modeled in various ways in the literature. Homburg (1990) and Breyer and Straub (1993) assume that taxes distort the labor-leisure decision so that a decrease in the contribution rate for the PAYG system will increase labor supply and, therefore, restrict the loss in revenue for financing the pension benefits. ${ }^{6}$ Pemberton (2000), however, considers the case where a conversion policy goes along with an income tax being replaced by a consumption tax. Then young individuals under the conversion policy have an incentive to save more than under the income tax, which provides the means to compensate the older generations when the PAYG system is abolished.

\footnotetext{
${ }^{5}$ This assumption may look strange as pension reform issues are often discussed in the context of population aging. In this paper, however, we focus on the international spillover effects of pension reform. In another paper, i.e., Adema et al. (2008), we discuss the spillovers of pensions under aging.

${ }^{6}$ It should be noted here that the existence of excess burdens in taxation cannot be the prime motive for converting the PAYG system into a fully funded system. The excess burden arises because the individual link between pension benefits and contributions is broken. The reason for this is that the pension system is also used for intragenerational redistribution. As proved by Fenge (1995) and Brunner (1996), in a PAYG system in which such a link exists, the system is Pareto efficient, even if contributions are a proportional tax on labor income. Such PAYG systems exist. For instance, as noted by Sinn (2000), Germany has had a PAYG system since 1957 where benefits are proportional to contributions, and so a Pareto improving transition to a funded system is not possible in Germany. Sinn (2000) and Belan and Pestieau (1999) give overviews of the issue. Their conclusion in the words of the last authors is that "reduced distortions can be achieved without privatization".
} 
Analogously, Belan et al. (1998) offer the first generation a subsidy on the return on their savings. Yet another way of modeling can be found in Köthenbürger and Poutvaara (2006) who assume that a decrease of taxation goes along with an increase in the value of a fixed factor.

Instead of explicitly specifying how behavior is affected when the excess burden of the premium contributions is lifted, we assume that the tax base is constant and independent of the size of the contribution. The existence of an excess burden under the PAYG system is modeled by assuming a so-called "iceberg" formulation of tax distortions (as in, e.g., Casamatta et al. 2000 and Perotti 2001), that is, for a given tax imposed on young individuals, only $\tau_{t}^{P}-\left(\tau_{t}^{P}\right)^{2}$ can be redistributed, so $\left(\tau_{t}^{P}\right)^{2}$ is "wasted." For a tax on elderly individuals, however, such a waste does not occur. This specification of the excess burden of the tax is a short cut for the labor-supply interpretation. Regarding this interpretation, it should be the case, as we assume, that taxing the young leads to tax revenue losses if the young curtail their labor-supply efforts as a result of the tax. But when the elderly are retired, taxes cannot have an effect on their labour-supply behavior, and so there is no excess burden. ${ }^{7}$

In general, in the initial steady state, the pension benefit of an old individual is equal to: 8

$$
z^{P}=\tau^{P}-\xi\left(\tau^{P}\right)^{2}
$$

where $\xi=1$ implies that the PAYG tax leads to an excess burden, and where $\xi=0$ refers to the situation where the financing of the PAYG scheme is not distortionary. For the moment, we develop the model in the absence of distortions so that $\xi=0$ and $z^{P}=\tau^{P}$ in the initial steady state. In Sect. 4 , we consider the case where $\xi=1$.

At $t=-1$, the government in country $P$ announces that it will reform its pension system in the next period $(t=0)$. Individuals take the economic consequences of the reform into account when they make their optimizing decisions in period $t=-1$. A pension reform leads to a lower contribution level and lower benefits. We model this as follows:

$$
\begin{gathered}
\tau_{t}^{P}=\mu_{t} \tau^{P} \\
z_{t}^{P}=\lambda_{t} \tau^{P}
\end{gathered}
$$

where $\mu_{t}<1$ and $\lambda_{t} \leq 1$.

One of the crucial issues in pension reform is whether or not the (partial or complete) switch to funding is accompanied by a compensation for the older generations. We consider both possibilities. In the first case, there is no compensation: benefits and contributions simultaneously decrease by the same amount. The elderly individuals at the time of the reform lose as a consequence, while the current and future young individuals fully gain from the higher rate of return on their contributions under the funded system.

\footnotetext{
${ }^{7}$ The tax on the elderly can be seen, for example, as a short-cut for a tax on old-age consumption that is nondistortionary.

${ }^{8}$ By omitting time subscripts, we denote the initial steady state value of the respective variable.
} 
In the second case, the elderly are compensated, implying that $\mu_{t}<\lambda_{t}$ will hold during the initial periods of the reform. We assume that public debt, $\left(b_{t}^{P}\right)$, is used to finance the shortfall in contributions. It is assumed that the government issues one-period debt, which yields the same rate of interest as capital. At a later stage, additional contributions $\left(\tau_{t}^{B}\right)$ are raised to finance the interest obligations on the debt, so as to keep debt per worker constant. With debt, therefore, the budget constraint of the government (public debt dynamics) in per capita terms is:

$$
b_{t+1}^{P}=\left(1+r_{t}\right) b_{t}^{P}+z_{t}^{P}-\tau_{t}^{P}-\tau_{t}^{B}
$$

If part of the benefits are financed by government debt, we assume that at a certain point in time benefits match contributions again, i.e., the benefits should have decreased as: $\lambda_{t}=\mu_{t}<1$. So the PAYG system is balanced again, but at a permanently lower level. At the moment that contributions and benefits are equal again, the government introduces $\tau_{t}^{B}$, such that debt per worker is stabilized from then on. Furthermore, we assume that there is no government debt in the initial steady state $\left(b^{P}=0\right)$, so that $\tau^{B}$ is zero too.

In country $F$, the government invests the contributions of the young and returns them with interest in the next period in the form of transfers to the then old agents. The funded scheme has fixed contributions, which implies that the system is actuarially fair for every individual and contributions to the pension scheme are exactly offset by an equal reduction in private savings. This means that the funded pension system is neutral and the economy behaves in exactly the same way as if there were no pension scheme. Therefore, we do not distinguish between contributions to the funded pension scheme and private savings, that is, pension contributions are included in total savings $s_{t}^{F}$.

\subsection{Households}

Lifetime utility of a representative individual born at $t$ is given by the following separable utility function: ${ }^{9}$

$$
U\left(c_{t}^{y, i}, c_{t+1}^{o, i}\right)=u\left(c_{t}^{y, i}\right)+\frac{1}{1+\rho} v\left(c_{t+1}^{o, i}\right) \quad(i=P, F)
$$

where $\rho>0$ stands for the (constant) pure rate of time preference of an individual, $c_{t}^{y, i}$ is consumption when young, and $c_{t+1}^{o, i}$ is consumption in the second period of life.

Young agents inelastically supply one unit of labor. The budget constraints in the PAYG country are as follows:

$$
\begin{aligned}
c_{t}^{y, P} & =w_{t}-\tau_{t}^{P}-s_{t}^{P} \\
c_{t+1}^{o, P} & =\left(1+r_{t+1}\right) s_{t}^{P}+z_{t+1}^{P}-\tau_{t+1}^{B}
\end{aligned}
$$

\footnotetext{
${ }^{9}$ We assume that the felicity functions $u\left(c_{t}^{y, i}\right)$ and $v\left(c_{t+1}^{o, i}\right)$ satisfy the Inada conditions.
} 


$$
\begin{aligned}
& c_{t}^{y, P}=w_{t}-\tau_{t}^{P}-\tau_{t}^{B}-s_{t}^{P} \\
& c_{t+1}^{o, P}=\left(1+r_{t+1}\right) s_{t}^{P}+z_{t+1}^{P}
\end{aligned}
$$

The government in country $P$ can either levy the additional tax to stabilize government debt $\left(\tau_{t}^{B}\right)$ on the elderly (6b) or on the working people (7a). The budget constraints for the funded country are same, except that $\tau_{t}^{P}=\tau_{t}^{B}=z_{t+1}^{P}=0$.

Maximizing lifetime utility subject to the budget constraints gives the following expression for individual optimal consumption in both countries:

$$
u^{\prime}\left(c_{t}^{y, i}\right)=\frac{1+r_{t+1}}{1+\rho} v^{\prime}\left(c_{t+1}^{o, i}\right) \quad(i=P, F)
$$

where $u^{\prime}\left(c_{t}^{y, i}\right)=\frac{\mathrm{d} u\left(c_{t}^{y, i}\right)}{\mathrm{d} c_{t}^{y, i}}$ is the marginal utility of young-age consumption, and $v^{\prime}\left(c_{t+1}^{o, i}\right)=\frac{\mathrm{d} v\left(c_{t}^{o, i}\right)}{\mathrm{d} c_{t}^{o, i}}$ is the marginal utility of old-age consumption. For future reference, we define the elasticity $\sigma_{t}^{i} \equiv-\frac{v^{\prime}\left(c_{t}^{o, i}\right)}{c_{t}^{o, i} v^{\prime \prime}\left(c_{t}^{o, i}\right)}, i=F, P$ with $v^{\prime \prime}\left(c_{t}^{o, i}\right)$ the secondorder derivative of felicity when old. The value of these elasticities in the steady state is important for the effects of a reform. In particular, we exclude extremely low values of $\sigma$ as these imply large increases in savings in reaction to a decrease in the interest rate.

\subsection{Equilibrium international capital market}

We assume that the two countries have a common capital market, i.e., capital is perfectly mobile. In this respect, our paper differs from Casarico (2001), who analyzes the effects of the integration of capital markets of two countries that differ in the degree of funding of their pension systems. ${ }^{10}$

Individuals invest their savings either in the home country or abroad. Their portfolios will be composed such that interest rates are equalized. Equilibrium in the international capital market is given by:

$$
s_{t}^{P}+v s_{t}^{F}=(1+v) k_{t+1}+b_{t+1}^{P}
$$

As old-age consumption in country $P$ is partly financed by a transfer from the young, while in country $F$ old-age consumption has to be completely financed by own savings, the latter country has higher savings than country $P$, implying that country $F$ exports capital abroad.

\footnotetext{
${ }^{10}$ Casarico (2001) also shortly touches upon the issue of pension reform in an open economy. We, however, consider different pension reform scenarios, derive the full dynamic path for the capital-labor ratio, show simulation graphs to clarify the mechanisms of the model further, and distinguish between the case where PAYG contributions are distorting and the case where the PAYG taxes do not lead to distortions.
} 


\section{Pension reform under Pareto efficiency}

This section investigates the spillover effects of a pension reform in the PAYG country, under the assumption that the PAYG system is Pareto efficient, i.e., taxes are nondistortionary. This means that there is a trade-off between the utility of different generations in implementing the reform. We consider three different types of reforms. In the first reform, the government in the PAYG country does not compensate the elderly at the time of the reform (Sect. 3.1). In the second and third reform, we analyze the effects in case the government fully compensates the current old (Sect. 3.2). In that case, government debt is created and the extra tax needed to pay the interest obligations on the debt can either be levied on the pensioners or on the workers.

For all cases considered, we are able to calculate analytically the effect of a pension reform on the common capital stock. We employ the method of comparative dynamics, adopted from (Judd 1982). The processes for $\mu_{t}$ and $\lambda_{t}$ are given by:

$$
\begin{aligned}
\mu_{t} & =1+\pi g_{t} \\
\lambda_{t} & =1+\pi f_{t}
\end{aligned}
$$

where $g_{t}<0$ and $f_{t} \leq 0$ describe the time pattern of a perturbation of $\mu_{t}$ and $\lambda_{t}$ from their steady-state values and $\pi$ reflects the magnitude of this perturbation. The effects of a pension reform can be traced by linearizing the capital-accumulation (9) with respect to $\pi$ around the initial steady state. The resulting first-order difference equations for $k_{t}$ describe the capital-labor ratio changes over time and the determining factors. Moreover, we produce numerical simulations in order to illustrate the mechanics of the model. The qualitative results of these simulations are robust for changes in the adopted values of the parameters. ${ }^{11}$

\subsection{No compensation for the current old}

At $t=-1$, the government announces that it will decrease both the contributions to the PAYG system $\left(\tau_{t}^{P}\right)$ and the pension benefits $\left(z_{t}^{P}\right)$ permanently in the next period $(t=0) .{ }^{12}$ So, the old at $t=0$ bear all the costs of the reform.

The change in the capital-labor ratio To analyze the international spillover effects, we compare the effects of reform when the two economies have a joint capital market (indicated by superscript $P F$ ) to the situation where the two economies are closed (indicated by superscripts $P$ and $F$, respectively). Obviously, in country $F$, nothing happens when it is a closed economy, as there is no need for reform.

\footnotetext{
${ }^{11}$ We derived numerically the nonlinear transition path, and compared the numerical results with those found with the method of comparative dynamics. The accuracy of the linearized path was quite satisfactory with a relative error of one percent at most. This is in line with the findings by Meijdam and Verhoeven (1998). They conclude that using comparative dynamics in a dynamic model is just as accurate as using comparative statics in a static model.

${ }^{12}$ This means that $g_{0}=g_{1}=\cdots=g_{\infty}<0$ and $f_{t}=g_{t}<0$. This could either be a full privatization $\left(g_{t}=f_{t}=-1\right)$ or a partial privatization $\left(-1<g_{t}=f_{t}<0\right)$. 
Using the method described above, we obtain the following first-order difference equation for the evolution of the capital-labor ratio when the two economies have a joint capital market: ${ }^{13}$

$$
\begin{aligned}
\frac{\partial k_{t+1}^{P F}}{\partial \pi}= & \frac{\left[\frac{1}{\alpha^{P}}-1+v\left(\frac{1}{\alpha^{F}}-1\right)\right] k f^{\prime \prime}(k)}{\Delta} \frac{\partial k_{t}^{P F}}{\partial \pi}+\frac{\left(\frac{1}{\alpha^{P}}-1\right) \tau^{P}}{\Delta} g_{t} \\
& -\frac{\tau^{P}}{\alpha^{P} \Delta(1+r)} f_{t+1}
\end{aligned}
$$

with $\Delta \equiv 1+v+f^{\prime \prime}(k)\left(\frac{\beta^{P}}{\alpha^{P}}+v \frac{\beta^{F}}{\alpha^{F}}\right)$, and $\alpha^{i} \equiv 1+\frac{1+\rho}{(1+r)^{2}} \frac{u^{\prime \prime}\left(c^{y, i}\right)}{v^{\prime \prime}\left(c^{o, i}\right)}>1, i=F, P$. Note that $\frac{1}{\alpha^{i}}<1$ can be interpreted as the propensity to consume out of lifetime income when young (for a given interest rate). The $\beta$ 's indicate the effect of a change in the interest rate on consumption when young (and thus on savings) and are defined as $\beta^{F} \equiv \frac{\left(1-\sigma^{F}\right) c^{o, F}}{(1+r)^{2}}, \beta^{P} \equiv \frac{\left(1-\sigma^{P}\right) c^{o, P}-z^{P}}{(1+r)^{2}}$. Note that in case of logarithmic utility functions $\alpha^{i}=\frac{2+\rho}{1+\rho}, \beta^{F}=0$ and $\beta^{P}=\frac{-z^{P}}{(1+r)^{2}}, i=P, F$. The first-order difference equation for country $P$ when it is closed is given by:

$$
\frac{\partial k_{t+1}^{P}}{\partial \pi}=\frac{\left[\frac{1}{\alpha^{P}}-1\right] k f^{\prime \prime}(k)}{\Delta^{P}} \frac{\partial k_{t}^{P}}{\partial \pi}+\frac{\left(\frac{1}{\alpha^{P}}-1\right) \tau^{P}}{\Delta^{P}} g_{t}-\frac{\tau^{P}}{\alpha^{P} \Delta^{P}(1+r)} f_{t+1}
$$

with $\Delta^{P} \equiv 1+f^{\prime \prime}(k) \frac{\beta^{P}}{\alpha^{P}}$. We assume ${ }^{14} 0<\Delta^{P}<\Delta$. By comparing the capital-labor ratio changes in the closed-economies case (13) with the change in the capital-labor ratio when the two countries have integrated capital markets (12), we derive the pure spillover effects of pension reform in a common capital market. ${ }^{15}$

At the time of the announcement $(t=-1)$, young individuals living in country $P$ increase their savings because they know they will receive a lower pension benefit, i.e., $f_{0}<0$. As a result, the reform leads to a positive change in the capital-labor ratio at $t=0$, as $\frac{\partial k_{0}^{P F}}{\partial \pi}=\frac{-\tau^{P}}{\alpha^{P} \Delta(1+r)} f_{0}>0$ (12). Note that (given that $\Delta>\Delta^{P}$ ) this effect is larger in case of a closed economy (see (13)). The increase in the common capital-labor ratio at $t=0$ leads to higher wages, which engenders higher savings in both countries. Due to these higher savings, the capital-labor ratio continues to rise (the first term in $(12)>0$ ). Citizens in the PAYG country have an additional incentive to save more because as of $t=0$, contributions to the PAYG system fall (second term in $(12)>0$ ), and they will receive lower benefits. So, we have the general result (see also Fig. 1 where we show the change in the capital-labor ratio for the different cases $):{ }^{16}$

\footnotetext{
${ }^{13}$ In Appendix A.1, we show the derivation of this expression.

${ }^{14}$ In case of logarithmic utility, this condition always holds. For the more general case, this condition holds for a wide range of parameter values.

${ }^{15}$ To exclude the effects of integration, it is assumed that the initial steady state is the same in all cases.

${ }^{16}$ The graphs are based on simulations with logarithmic utility functions and countries of equal size $(v=1)$. The initial value of the tax rate is 0.2 . It is assumed that half of the PAYG system is privatized,
} 
Fig. 1 Change in $k_{t}$

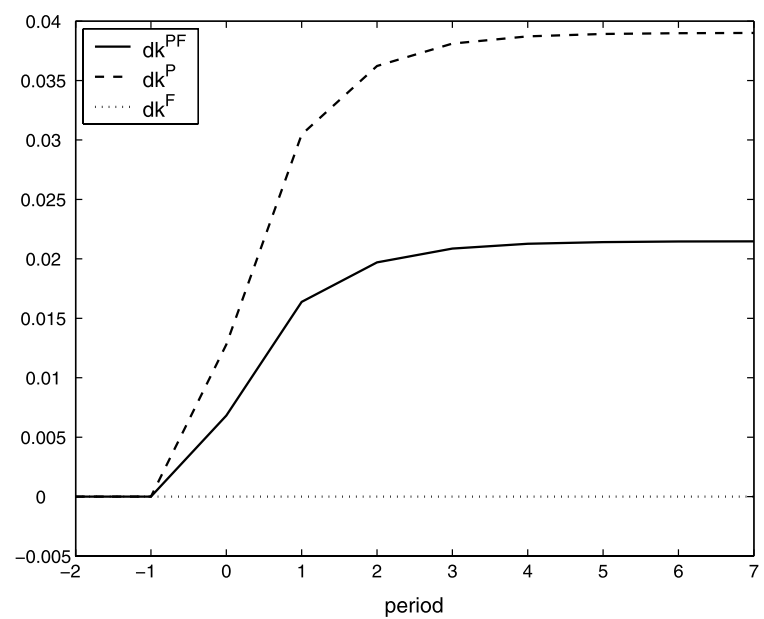

Result 1 In case the elderly are not compensated at the time of a given pension reform, the capital-labor ratio in country $P$ increases less in case it has a common capital market with a funded country compared to the case where it is closed, as part of the extra savings flow to country $F$.

In Fig. 1, the two economies have the same size $(v=1) .{ }^{17}$ However, as most EU countries mainly use PAYG pension schemes, the group of countries that has sizeable funded pensions can be considered as relatively small. If the group of funded countries is relatively small (i.e., $v<1$ ) and a large group of countries with extensive PAYG schemes reform their pension system, the spillover effects for the funded countries will be larger. For the PAYG countries, however, it holds that the larger they are relative to the funded countries, the more the effects of the reform resemble the effects of a closed economy.

The change in consumption and utility When we know the change in the capitallabor ratio, we can derive the changes in all other variables. The analytical derivations are presented in Appendix A.2 for the consumption and utility effects in country $F$. Here, we only show simulation graphs. The change in consumption when young and old in the two countries is displayed in Figs. 2 and 3, respectively. The spillover effects for consumption are summarized in the following results:

that is, from $t=1$ onwards, both the contributions and the benefits fall by $50 \%$ permanently. The results do not qualitatively change when the PAYG system is totally privatized, however. Moreover, we used the following production function, $f\left(k_{t}\right)=k_{t}^{0.3}$. Capital depreciates at $5 \%$ per year, and assuming that one period is 30 years, this means that $\delta=1-(0.95)^{30}=0.7854$. Agents are relatively patient with a time preference of $1.2 \%$ per year, so that $\rho=(1.012)^{30}-1=0.4303$.

${ }^{17}$ In the steady state $k=0.13$, which implies that the capital-labor ratio rises by about $17 \%$ in the open economy case. 
Fig. 2 Change in $c_{t}^{y, i}$

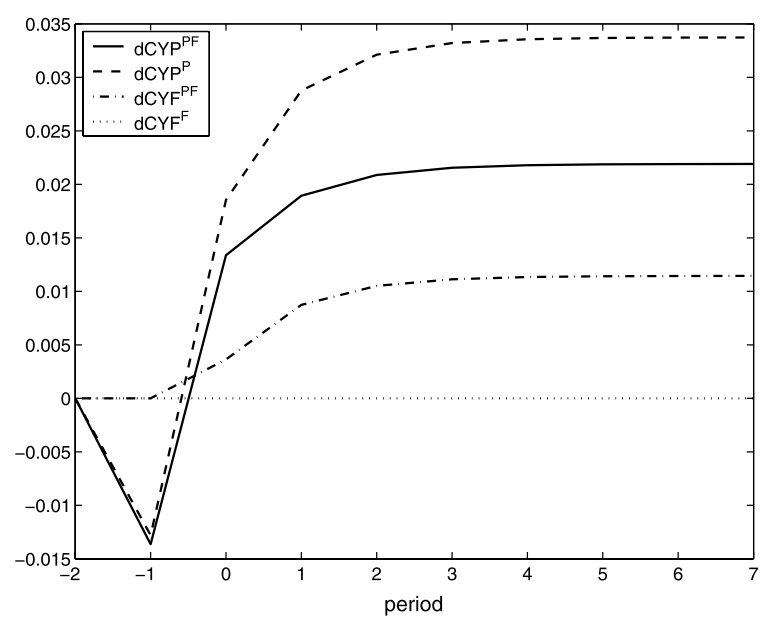

Fig. 3 Change in $c_{t}^{o, i}$

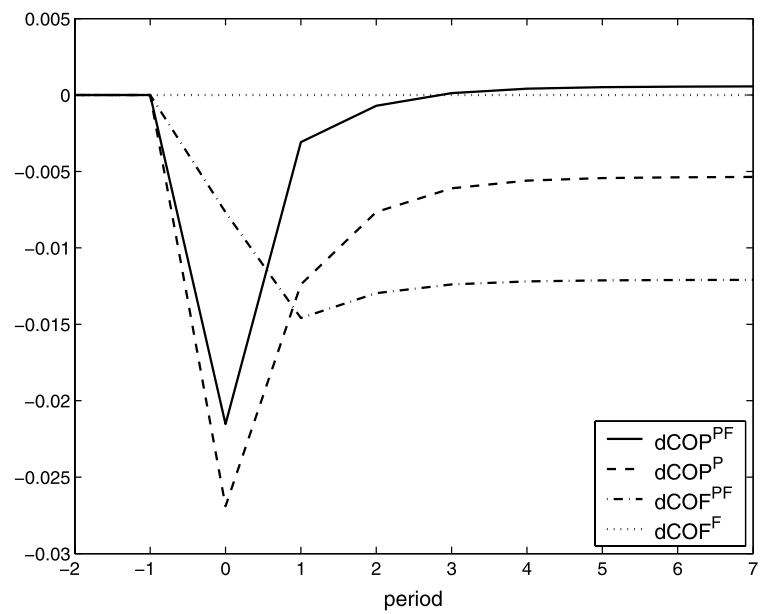

Result 2 In case there is no compensation for the current old:

(a) The reform in country $P$ implies an increasing capital-labor ratio and higher wages, which enhances the consumption possibilities for the young in country $F .^{18}$

(b) The fall in the interest rate, however, lowers the return of the savings of old people living in country $F$, which has a negative effect on their consumption. Savings in country $F$ do not rise sufficiently to offset the negative effects of the lower interest rate in the long run, so that the consumption of the elderly in the non-reforming country decreases due to the reform. ${ }^{19}$

${ }^{18}$ This is the case if $\beta^{F}<k$, see Appendix A.2 for details.

${ }^{19}$ As shown in Appendix A.2, this result holds if $s^{F}>\frac{\sigma^{F}\left(\alpha^{F}-1\right)(1+r)\left(k-\beta^{F}\right)}{\alpha^{F}}$. 
Fig. 4 Change in $U_{t}^{i}$

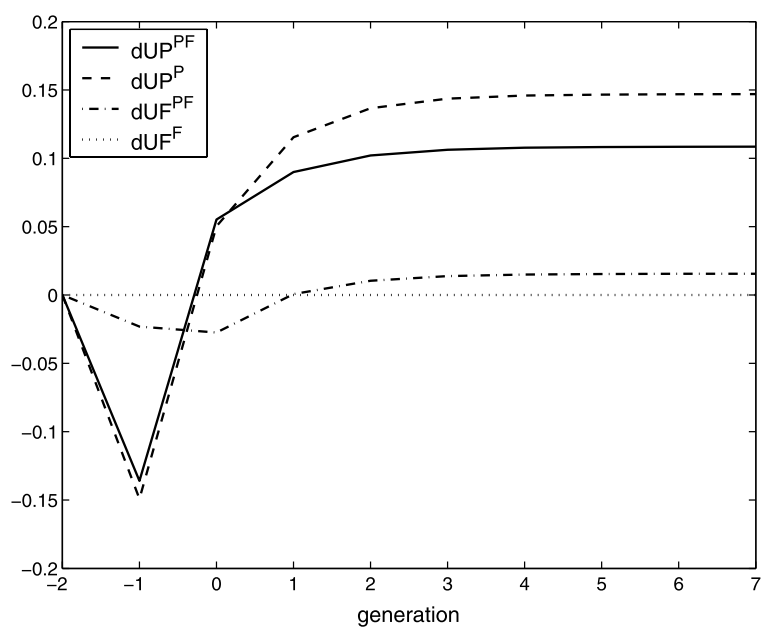

The changes in lifetime utility are shown in Fig. 4, lifetime utility rises in the long run. However, this type of pension reform, in which benefits are decreased without compensation, will obviously hurt the elderly in country $P$ at the time of the reform. It is, however, interesting to note that this loss spills over to the elderly in country $F$ as well. In particular, we have: ${ }^{20}$

Result 3 In case the current elderly in country $P$ are not compensated, the generation in country $F$ born at the time of the reform $(t=0)$ may experience a loss, while this is not the case for the same generation in country $P$. Later generations in country $F$ gain from the pension reform in country $P$, but the consumption gap between young and old people has increased.

The latter result is noteworthy. An important motive for introducing a reform is to get higher rates of return on pension contributions and, as a result, a higher retirement income. In the funded country, however, the result is just the opposite: the pensioners in the funded country will achieve lower incomes than if the PAYG country had not implemented a reform. The reason for this counterintuitive result is that the higher savings in the PAYG country, generated by the reform, lead to a fall in the interest rate and, therefore, lower returns on the pension contributions paid in the funded country.

\footnotetext{
${ }^{20}$ As shown in Appendix A.2 utility in the funded country rises in the long run if $s^{F}<k(1+r)$. Figure 13 in Appendix A.2 shows that this condition holds for a wide range of parameter values. The utility in the funded country decreases initially if the positive wage effect when young is outweighed by the negative effect on the interest rate (which may be relatively large because $k$ increases over time) when old. The condition for this is $s^{F}>\frac{k(1+r)}{\alpha^{P}(1+r)-r+\left[\frac{1}{\alpha^{P}}-1+v\left(\frac{1}{\alpha^{F}}-1\right)\right] k f^{\prime \prime} / \Delta}$. This condition holds as long as the production elasticity of capital is not too large $(\leq 0.5)$.
} 


\subsection{Compensation}

In the pension reform described in the previous section, the current elderly bear all the costs of the reform. It is probably more realistic to assume that the government compensates the current old, so that individuals have more time to adjust their behavior to the smaller PAYG system. Political economy arguments could also play a role for implementing such a reform policy. Cooley and Soares (1999), for example, argue that privatizing a PAYG system is only politically feasible in case a transition policy uses debt to finance the benefits during the transition period, shifting at least part of the cost to future generations. Therefore, in this and the next subsection, we assume that while contributions to the PAYG scheme fall permanently at $t=0$, benefits are kept constant in that period. This is again communicated one period before the reform actually takes place (at $t=-1$ ). The government also announces that at $t=1$ pension benefits will fall as much as the contributions, so that the PAYG system is balanced again from then on. ${ }^{21}$ Since taxes are lower than the benefits during one period $(t=0)$, there will be government debt in country $P$ at $t=1$. At the moment that contributions and benefits are equal again $(t=1)$, the government introduces an extra tax $\left(\tau_{t}^{B}\right)$ to pay the interest obligations on its debt, such that debt per worker is stabilized from then on. This extra tax can either be levied on the working people or on the elderly.

Tax levied on the future old When $\tau_{t}^{B}$ is levied on the elderly, starting at $t=1$, the pension reform is Pareto neutral, that is, there is no generation that gains or loses from the pension reform. The reason for this result is that savings in the PAYG country increase just as much as government debt increases. All that has happened is that the implicit debt inherent to the PAYG system has been made explicit. This is a standard result in the pension reform literature, see, for example, Verbon (1989), Breyer (1989) and Homburg (1990). So, we have: ${ }^{22}$

Result 4 In case the old at the time of the reform are fully compensated and the tax to finance the debt is levied on the future elderly, the capital-labor ratio remains constant over time.

A constant capital-labor ratio implies that consumption and utility also do not change. Moreover, there are no international spillover effects for the funded country.

Tax levied on the future young Instead of imposing $\tau_{t}^{B}$ on the elderly, the government can also levy the tax on the working people, starting at $t=1$. So, the first young generation under the reform, born at $t=0$, does not have to pay the debt tax, i.e., $\tau_{0}^{B}=0$, as $b_{0}^{P}=0$. Like the future young generations, they get the lower PAYG tax, but unlike the future young generations, they do not have to contribute to the com-

${ }^{21}$ This means that $g_{0}=g_{1}=\cdots=g_{\infty}<0$ and $f_{0}=0, f_{t}=g_{t}<0$ for $t>0$.

${ }^{22}$ More information and a formal proof of this result can be found in Appendix B.1. 
Fig. 5 Change in $k_{t}$

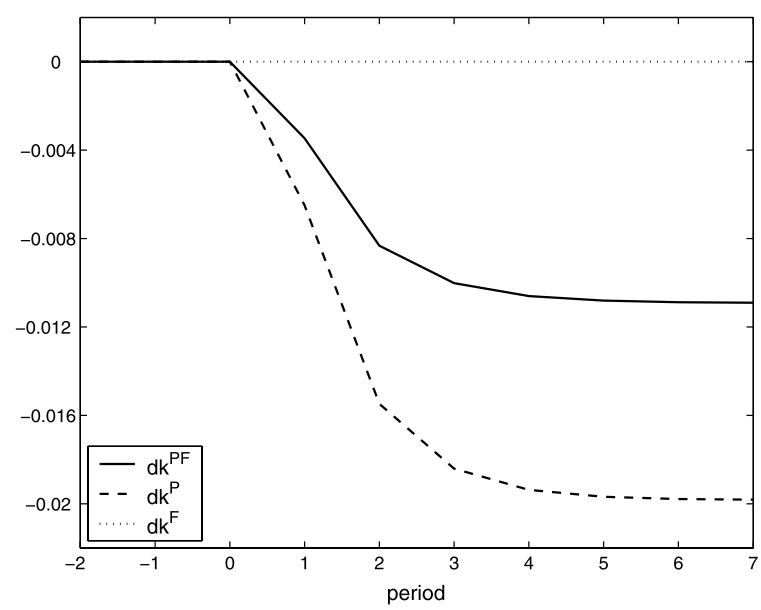

pensation the elderly at $t=0$ receive. The young generation at $t=0$, therefore, will get a windfall gain. ${ }^{23}$ This gives the following result: ${ }^{24}$

Result 5 In case there is full compensation for the elderly at the time of the reform and the debt tax is levied on the future workers, the capital-labor ratio will start decreasing in the period after the reform in country $P$. This in turn leads to capital flows from country $F$ to country $P$.

The intuition for this result is obvious. The first young generation under the reform consumes part of its gain in the first period, and saves part of it. As the gain this generation receives equals the created debt, the increase in savings at $t=0$ is lower than the created debt. In other words, the public debt crowds out part of the capital stock.

Future working generations get the lower PAYG tax, but also pay a debt tax $\tau_{t}^{B}$. Moreover, they inherit a lower capital-labor ratio, which leads to lower wages. Therefore, savings are lower and, as a result, the capital-labor ratio continues to decline. Because country $P$ can finance part of its government debt with savings of country $F$, the capital-labor ratio falls more when country $P$ does not have an integrated capital market with country $F$. This can be seen in Fig. 5 .

Notice that the results of this reform are exactly the opposite of the pension reform described in Sect. 3.1: the capital-labor ratio falls over time instead of rises. This implies that the effect on the other endogenous variables is also reversed. Actually, all simulation graphs are almost the mirror images of those of the pension reform in Sect. 3.1, the peaks are only one period later, because young individuals in the PAYG

\footnotetext{
${ }^{23}$ The government in the PAYG country may decide to implement the pension reform in this way for political economy reasons. For example, when it is assumed, as in Cooley and Soares (1999), that a reform is only implementable in case it is welfare-improving for a majority of the current population.

${ }^{24}$ More details and a formal proof of this result are given in Appendix B.2.
} 
Fig. 6 Change in $c_{t}^{y, i}$

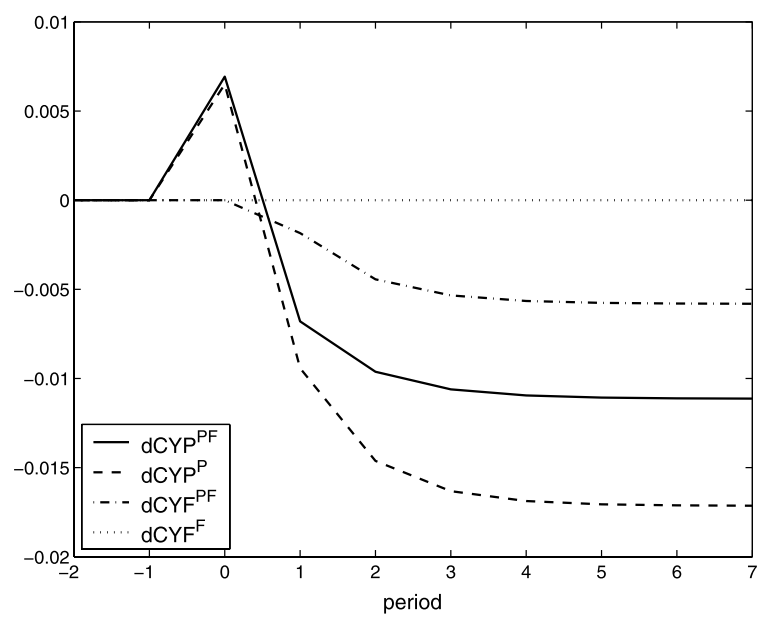

country do not adjust their behavior at $t=-1$. The main findings are as follows (see also Figs. 6, 7, 8): 25

Result 6 In case the elderly are fully compensated at the time of the reform and the tax to finance the debt is levied on the future workers:

(a) The pension reform in country $P$ leads to less consumption possibilities for the young in country $F$, while the elderly in this country gain.

(b) In the period after the reform both the elderly and the working people in the funded country gain from the pension reform in the PAYG country. In the long run, however, people in the funded country experience negative spillover effects.

So, the fact that they have a common capital market with country $F$ protects the generations living in country $P$ to some extent, as part of the burden of this reform policy is transmitted to country $F$ via the capital market. ${ }^{26}$

\subsection{Concluding remarks}

In general, we conclude the following: In case the PAYG system is Pareto efficient and the government in the PAYG country implements a reform that leads to losses for at least one generation, these losses will be transmitted to the funded country via the capital market. It should be noted that the pension reforms analyzed in this section are extreme, in the sense that no compensation at all or full compensation is granted at the time of the reform. Of course, it is possible to have pension reforms where the

\footnotetext{
${ }^{25}$ The analytical framework of Appendix A.2 still applies, as all the expressions for the change in consumption and utility are expressed as a function of the capital-labor ratio.

${ }^{26}$ Of course, the government in the PAYG country could decide to stabilize the debt and levy $\tau_{t}^{B}$ in a later period, so that even more generations get a windfall gain. Government debt would crowd out a larger part of the capital stock and the long-term losses would be larger. However, our central result that the funded country shares in the gains and losses of the reform in the PAYG country would not change.
} 
Fig. 7 Change in $c_{t}^{o, i}$

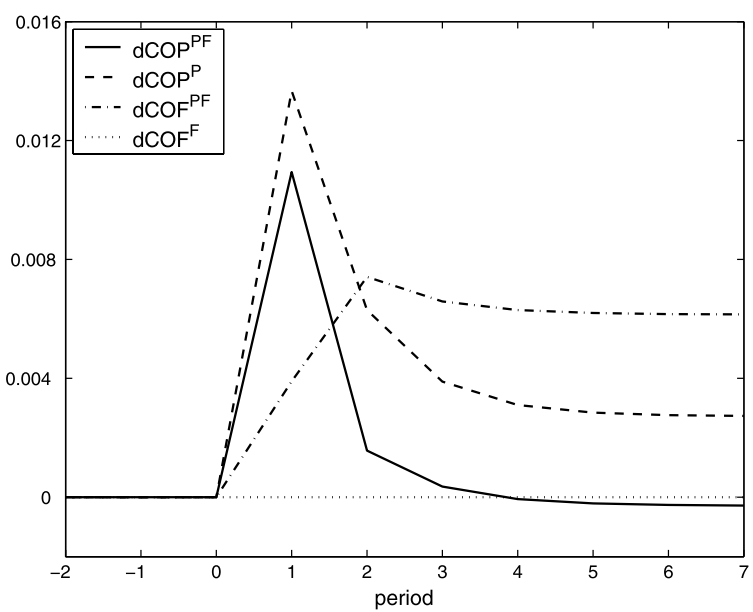

Fig. 8 Change in $U_{t}^{i}$

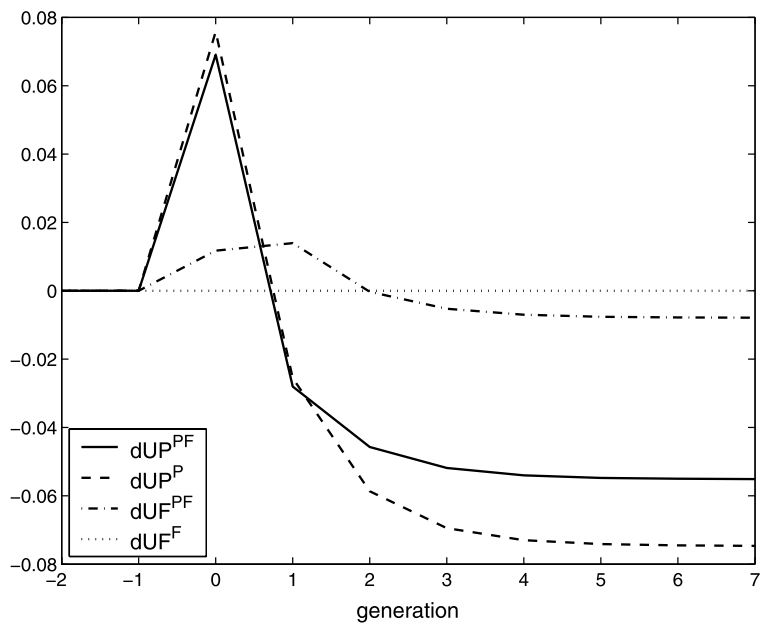

elderly are partly compensated. However, such scenarios will not change the general conclusion from our analysis that a reform policy in one country unavoidably spills over to other countries.

\section{Pareto-improving pension reform}

In this section, we analyze the international spillover effects of a pension reform in the PAYG country in case there is scope for a Pareto improvement, due to a distortionary PAYG tax. As explained in Sect. 2.2, we model the excess burden as a (quadratic) loss of tax revenue. This corresponds to $\xi=1$ in (1), i.e., $z^{P}=\tau^{P}-\left(\tau^{P}\right)^{2}$, so $\left(\tau_{t}^{P}\right)^{2}$ is wasted. We start from the Pareto neutral pension reform scenario of the previous section. So, the government compensates the elderly at the time of the reform completely, and then from $t=1$ onward imposes an extra tax on the pensioners to pay the 
Fig. 9 Change in $k_{t}$

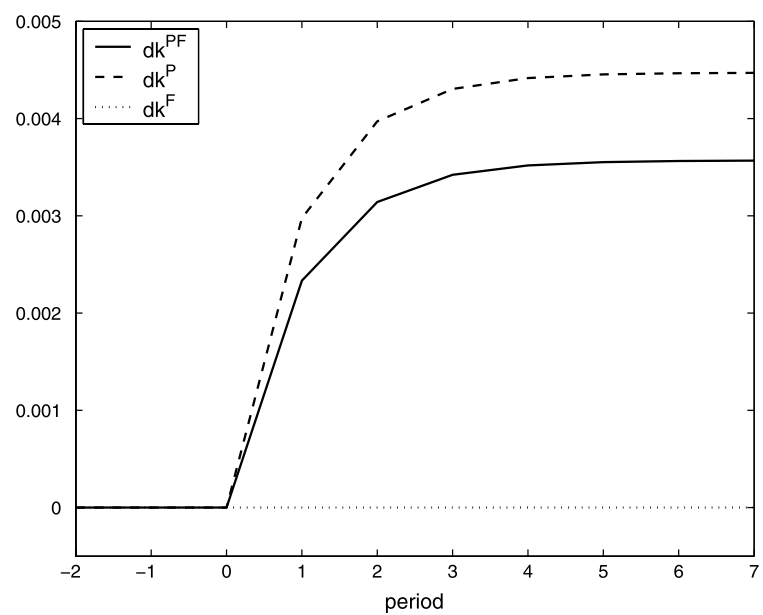

interest obligations on the debt in order to keep debt per capita constant. The budget constraint of the government (4) changes to:

$$
b_{t+1}^{P}=\left(1+r_{t}\right) b_{t}^{P}+z_{t}^{P}-\left(\tau_{t}^{P}-\left(\tau_{t}^{P}\right)^{2}\right)-\tau_{t}^{B}
$$

As argued earlier, we assume that the debt tax on the elderly, $\tau_{t}^{B}$, does not imply an excess burden, given the labor-supply motivation for the excess burden. Now we can state the following: 27

Result 7 In case the PAYG tax implies an excess burden, a pension reform in the $P A Y G$ country where the elderly are compensated and the debt tax is levied on the pensioners leads to an increase in the capital-labor ratio in the period after the reform. A higher capital-labor ratio in turn leads to higher wages and savings, so that the capital-labor ratio continues to increase.

We also show this in Fig. 9. The intuition behind this result is that when PAYG taxes induce an excess burden, abolishing (part of) the PAYG system leads to efficiency gains, so that the capital-labor ratio actually rises, instead of staying constant (as was the case in Result 4). It is then obvious that this reform leads to a Pareto improvement in the PAYG country. This can indeed be seen in Fig. 12, all generations get a higher utility. In the funded country, ${ }^{28}$ however, only consumption of the working people increases (see Fig. 10). The elderly in the nonreforming country get less consumption possibilities (see Fig. 11), mainly because the interest rate decreases after an increase in $k_{t}$. For the generation born at the time of the reform consumption when young does not change, while they can consume less at their oldage. This necessarily implies that this generation loses from the pension reform in the

\footnotetext{
${ }^{27}$ In Appendix $\mathrm{C}$ this is formally derived.

${ }^{28}$ Appendix A. 2 shows the analytical framework for the change in consumption and utility.
} 
Fig. 10 Change in $c_{t}^{y, i}$

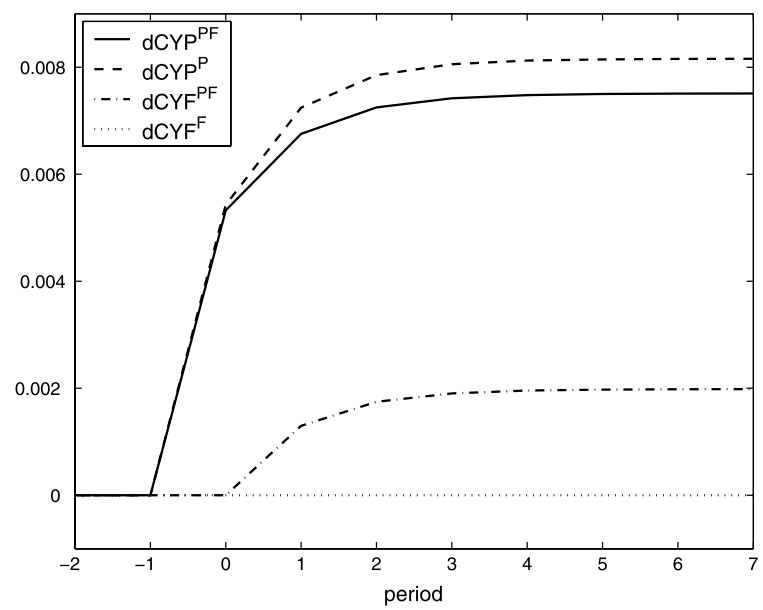

Fig. 11 Change in $c_{t}^{o, i}$

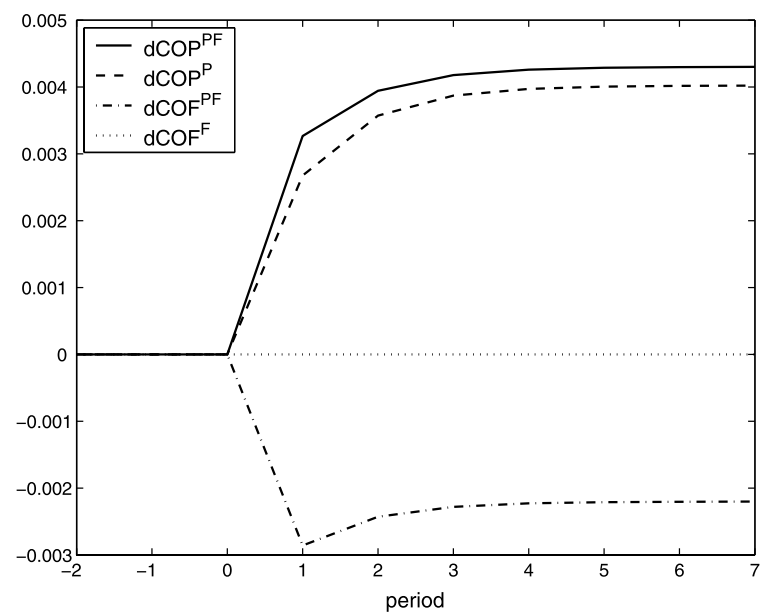

other country (see Fig. 12). All later generations in country $F$ gain from the pension reform in country $P$. So, we have the following main result:

Result 8 A Pareto-improving pension reform in country $P$ does not necessarily lead to a Pareto improvement in the funded country: the generation born at the time of the reform is hurt by the pension reform in the PAYG country.

\section{Concluding remarks}

Currently, in many countries with an extensive pay-as-you-go (PAYG) financed public pension system, reforms are considered to finance a larger part of the future pension benefits by accumulated funds. A central conclusion emerging from our paper is that in a common capital market the effects of such a pension reform in a PAYG 
Fig. 12 Change in $U_{t}^{i}$

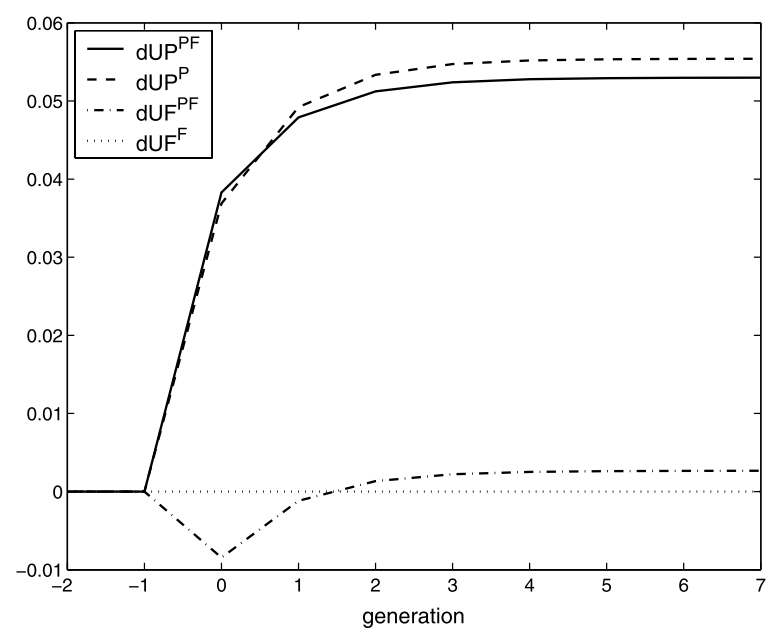

country spills over to countries with a fully funded pension system. In Europe, e.g., differences in financing methods of pension systems abound. For instance, countries like Germany and Italy have extensive PAYG-financed parts in their pension system, while in the UK and the Netherlands the larger part of the pension benefits are financed out of accumulated assets. The message of our paper is that the latter countries cannot insulate themselves from the effects of reform measures in the former countries. In the European pension debate, these spillover effects of pension reform have not been an issue until, now, as far as we know. Yet, the consequences of pension reform in a PAYG country can be rather adverse for a funded country as we have shown in this paper. Some key results illustrate this.

First, consider the case where the PAYG country compensates the elderly during the transition phase, and the PAYG system is Pareto efficient. The introduction of public debt, necessary to finance the compensation during the transition phase of the reform, will lead to crowding out of the capital stock in both the PAYG and the funded country, as soon as one generation is allowed to gain during the transition. As a result, future generations in both types of countries will lose under this reform policy.

Second, if a PAYG country reforms its public pension system such that its own future generations gain, then, although future generations in the funded country gain as well, the distribution of consumption between young and old individuals at a certain time will change at the expense of old individuals. In the funded country the elderly will even consume less in absolute amounts after the reform. Although the deterioration of old-age consumption is the result of free choice by individuals in the funded country, the resulting consumption allocation between young and old individuals might not be desirable from a societal point of view.

Third, we have shown that if excess burdens in tax collection enable a Paretoimproving pension reform in the PAYG country, during the transition phase some initial generations in the funded country might suffer a loss under the reform nevertheless. In other words, a reform policy that appears to be Pareto improving for the PAYG country considered separately, does not have to be Pareto improving after taking into account the international spillover effects. 
Obviously, our model has oversimplified the real world in many ways, and the issue of spillover effects of pension reform merits further study in especially larger and more applied models. Yet, we think that our central result, i.e., that pension reform in PAYG countries can have adverse effects on the welfare of some generations, or some type of individuals in funded countries will remain to stand out in a more general model. The obvious policy conclusion from our model is, therefore, that in a common market like the EU, decisions on pension reform in the countries with a large PAYG scheme cannot be taken without considering the effects for nonreforming (funded) countries. In particular, dependent on the type and size of reform in the PAYG countries, compensation for the nonreforming countries might be necessary.

Acknowledgements We are grateful for useful comments from John Wilson, Lans Bovenberg, Marko Köthenbürger, Pierre Pestieau, Leon Bettendorf, Sweder van Wijnbergen and two anonymous referees. Furthermore, we would like to thank the participants of the NAKE research day, Amsterdam, The Netherlands, October 2005, the 7th RTN workshop on "the Economics of Ageing", Venice, Italy, October 2005, the CEBR/CESifo conference on Pension Reform in Copenhagen, Denmark, June 2005, and the Economics lunch seminar, Tilburg, The Netherlands, May 2005, for valuable comments and discussions.

Open Access This article is distributed under the terms of the Creative Commons Attribution Noncommercial License which permits any noncommercial use, distribution, and reproduction in any medium, provided the original author(s) and source are credited.

\section{Appendix A}

\section{A.1 Derivation first-order difference equation $k_{t+1}$}

In this appendix, we derive the first-order difference equation for the evolution of the capital-labor ratio given in (12). Linearising the capital-accumulation equation (9) with respect to $\pi$ around the initial steady state gives:

$$
\frac{\partial s_{t}^{P}}{\partial \pi}+v \frac{\partial s_{t}^{F}}{\partial \pi}=(1+v) \frac{\partial k_{t+1}}{\partial \pi}
$$

where we used the fact that $\frac{\partial b_{t+1}^{P}}{\partial \pi}=0$ in case the current old are not compensated. Then we derive expressions for $\frac{\partial s_{t}^{P}}{\partial \pi}$ and $\frac{\partial s_{t}^{F}}{\partial \pi}$, using (6)-(8) and the fact that $\frac{\partial \tau_{t}^{B}}{\partial \pi}=0$ :

$$
\begin{aligned}
\frac{\partial s_{t}^{P}}{\partial \pi} & =\frac{\alpha^{P}-1}{\alpha^{P}}\left[\frac{\partial w_{t}}{\partial \pi}-\frac{\partial \tau_{t}^{P}}{\partial \pi}\right]-\frac{1}{\alpha^{P}}\left[\beta^{P} \frac{\partial r_{t+1}}{\partial \pi}+\frac{1}{1+r} \frac{\partial z_{t+1}^{P}}{\partial \pi}\right] \\
\frac{\partial s_{t}^{F}}{\partial \pi} & =\frac{\alpha^{F}-1}{\alpha^{F}} \frac{\partial w_{t}}{\partial \pi}-\frac{1}{\alpha^{F}} \beta^{F} \frac{\partial r_{t+1}}{\partial \pi}
\end{aligned}
$$

where $\alpha^{i} \equiv 1+\frac{1+\rho}{(1+r)^{2}} \frac{u \prime \prime\left(c^{y, i}\right)}{v \prime \prime\left(c^{o, i}\right)}>1, i=F, P, \beta^{F} \equiv \frac{\left(1-\sigma^{F}\right) c^{o, F}}{(1+r)^{2}}$ and $\beta^{P} \equiv \frac{\left(1-\sigma^{P}\right) c^{o, P}-z^{P}}{(1+r)^{2}}$. $\frac{\partial w_{t}}{\partial \pi}$ and $\frac{\partial r_{t+1}}{\partial \pi}$ are given by:

$$
\frac{\partial w_{t}}{\partial \pi}=-k f^{\prime \prime}(k) \frac{\partial k_{t}}{\partial \pi}
$$




$$
\frac{\partial r_{t+1}}{\partial \pi}=f^{\prime \prime}(k) \frac{\partial k_{t+1}}{\partial \pi}
$$

Combining (15)-(19) and simplifying gives:

$$
\begin{aligned}
\frac{\partial k_{t+1}^{P F}}{\partial \pi}= & \frac{\left[\frac{1}{\alpha^{P}}-1+v\left(\frac{1}{\alpha^{F}}-1\right)\right] k f^{\prime \prime}(k)}{\Delta} \frac{\partial k_{t}^{P F}}{\partial \pi}+\frac{\left(\frac{1}{\alpha^{P}}-1\right)}{\Delta} \frac{\partial \tau_{t}^{P}}{\partial \pi} \\
& -\frac{1}{\alpha^{P} \Delta(1+r)} \frac{\partial z_{t+1}^{P}}{\partial \pi}
\end{aligned}
$$

with $\Delta \equiv 1+v+f^{\prime \prime}(k)\left(\frac{\beta^{P}}{\alpha^{P}}+v \frac{\beta^{F}}{\alpha^{F}}\right)$. Using (2)-(3) and (10)-(11), we know that:

$$
\begin{gathered}
\frac{\partial \tau_{t}^{P}}{\partial \pi}=\tau^{P} g_{t} \\
\frac{\partial z_{t+1}^{P}}{\partial \pi}=\tau^{P} f_{t+1}
\end{gathered}
$$

Substituting these two last expressions into (20) gives (12).

\section{A.2 Derivation Results 2 and 3}

In this appendix, we derive analytical expressions for the change in consumption and utility in the funded country. From these equations, we can infer the relationship between the change in the capital-labor ratio and consumption and utility. The framework also applies to the pension reform scenarios discussed in Sects. 3.2 and 4.

Result 2a: Change in consumption when young Linearizing the first-period budget constraint gives:

$$
\frac{\partial c_{t}^{y, F}}{\partial \pi}=\frac{1}{\alpha^{F}}\left[\beta^{F} f^{\prime \prime}(k) \frac{\partial k_{t+1}}{\partial \pi}-k f^{\prime \prime}(k) \frac{\partial k_{t}}{\partial \pi}\right]
$$

The first term between the brackets shows the effect of the lower interest rate resulting for the higher capital-labor ratio, which affects consumption when young negatively in case $\sigma^{F}<1$. The second term represents the positive wage effect. In the long run, it holds that $\frac{\partial k_{t+1}}{\partial \pi}=\frac{\partial k_{t}}{\partial \pi}=\frac{\partial k_{\infty}}{\partial \pi}$ and we can write:

$$
\frac{\partial c_{\infty}^{y, F}}{\partial \pi}=\frac{1}{\alpha^{F}}\left[\beta^{F} f^{\prime \prime}(k)-k f^{\prime \prime}(k)\right] \frac{\partial k_{\infty}}{\partial \pi}
$$

which is positive as long as $\beta^{F}<k$, implying that $\sigma^{F}$ should not be extremely low so that the positive wage effect dominates the negative interest rate effect in case $\sigma^{F}<1$. Simulations show that for realistic parameter values $\beta^{F}<k$. In case of a logarithmic utility function $\sigma^{F}=1$ and $\beta^{F}=0$, so that only the wage effect occurs and young-age consumption always rises. 
Result 2b: Change in old-age consumption Linearizing the second-period budget constraint gives:

$$
\frac{\partial c_{t+1}^{o, F}}{\partial \pi}=\left(\alpha^{F}-1\right)(1+r) \frac{\partial c_{t}^{y, F}}{\partial \pi}+\frac{c^{o, F} f^{\prime \prime}(k)}{(1+r) \sigma^{F}} \frac{\partial k_{t+1}}{\partial \pi}
$$

Substituting the previous equation and (23) and noting that $\frac{\partial k_{t+1}}{\partial \pi}=\frac{\partial k_{t}}{\partial \pi}=\frac{\partial k_{\infty}}{\partial \pi}$ gives the long-run change of old-age consumption:

$$
\frac{\partial c_{\infty}^{o, F}}{\partial \pi}=\left[\frac{\left(\alpha^{F}-1\right)(1+r)}{\alpha^{F}}\left(\beta^{F}-k\right)+\frac{s^{F}}{\sigma^{F}}\right] f^{\prime \prime}(k) \frac{\partial k_{\infty}}{\partial \pi}
$$

The first term between the brackets shows the positive effect of higher savings, the second term shows the negative effects of the lower interest rate. As $\frac{\partial k_{\infty}}{\partial \pi}>0$ and $f^{\prime \prime}(k)<0, \frac{\partial c_{\alpha}^{o, F}}{\partial \pi}<0$ if $\frac{(1+r) \sigma^{F}\left(\alpha^{F}-1\right)\left(k-\beta^{F}\right)}{\alpha^{F}}<s^{F}$. Simulations show that this condition holds for realistic parameter values. Note that this condition reduces to $\frac{k(1+r)}{2+\rho}<s^{F}$ in case of logarithmic utility. In that case, simulations show that the condition does not hold in case the production elasticity of capital is relatively large $(\geq 0.5)$.

Result 3: Change in utility Linearisation of the lifetime utility function and substitution of the first-order condition gives:

$$
\frac{\partial U_{t}^{F}}{\partial \pi}=u^{\prime}\left(c^{y, F}\right) f^{\prime \prime}(k)\left[-k \frac{k_{t}}{\partial \pi}+\frac{s^{F}}{1+r} \frac{\partial k_{t+1}}{\partial \pi}\right]
$$

Using that in the long run $\frac{\partial k_{t+1}}{\partial \pi}=\frac{\partial k_{t}}{\partial \pi}=\frac{\partial k_{\infty}}{\partial \pi}$, it follows that

$$
\frac{\partial U_{\infty}^{F}}{\partial \pi}=\frac{u^{\prime}\left(c^{y, F}\right) f^{\prime \prime}(k)}{1+r}\left[s^{F}-k(1+r)\right] \frac{\partial k_{\infty}}{\partial \pi}
$$

which is positive if $s^{F}<k(1+r)$. A rise in the capital-labor ratio has two opposing effects on the utility of individuals living in the funded country:

1. Country $F$ is a lender in the international capital market, which means that $s^{F}>$ $k(1+n)$. This implies that the lower interest rate that results for a higher capitallabor ratio hurts people living in the funded country.

2. A lower interest rate also implies, however, that the economy is closer to the Golden Rule point $(r=n)$, which has positive utility effects in case of dynamic efficiency $(r>n)$.

If $s^{F}>k(1+r)$, the first effect dominates the second, implying that an increase in the capital-labour ratio affects utility negatively. On the other hand, when $s^{F}<k(1+r)$, the second effect dominates the first and a higher capital-labor ratio leads to a higher utility in the funded country. 
Fig. $13 s^{F}-k(1+r)$

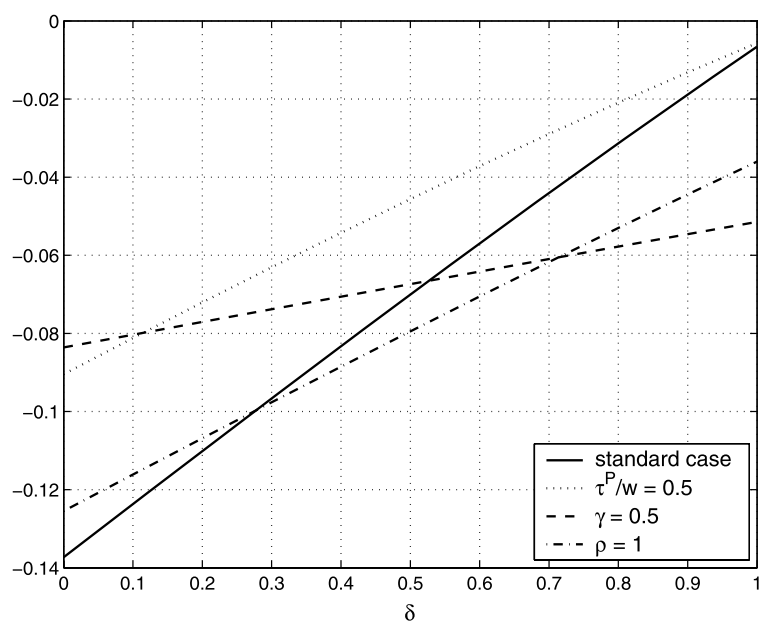

In Fig. 13, we present a graph that shows how the sign of $s^{F}-k(1+r)$ (vertical axis) changes for different parameter values. ${ }^{29}$ The horizontal axis shows the depreciation rate $(\delta)$. This graph shows that $s^{F}-k(1+r)<0$ for various values of the parameters, which means that the Golden Rule effect dominates the interest rate effect. This in turn implies that for realistic parameter values, a rise in the capital-labor ratio has positive utility effects in the funded country. ${ }^{30}$

For $t=0$, we can substitute the difference equation for the capital stock, (20), in (27), and use the fact that $\frac{k_{-1}}{\partial \pi}=0$ to find:

$$
\begin{aligned}
\frac{\partial U_{0}^{F}}{\partial \pi}= & u^{\prime}\left(c^{y, F}\right) f^{\prime \prime}(k)\left[-k+\frac{s^{F}}{1+r}\left(1+\left(\alpha^{P}-1\right)(1+r)\right.\right. \\
& \left.\left.+\frac{\left[\frac{1}{\alpha^{P}}-1+v\left(\frac{1}{\alpha^{F}}-1\right)\right] k f^{\prime \prime}(k)}{\Delta}\right)\right] \frac{k_{0}}{\partial \pi}
\end{aligned}
$$

Utility of people living in the funded country born at the time of the reform $(t=0)$ falls as long as $s^{F}>\frac{(1+r) k}{\alpha^{P}(1+r)-r+\frac{\left[\frac{1}{\alpha^{P}}-1+v\left(\frac{1}{\alpha^{F}}-1\right)\right] k f^{\prime \prime}(k)}{\Delta}}(<(1+r) k)$. This condition holds as long as the production elasticity of capital is not too large $(\leq 0.5)$.

\footnotetext{
${ }^{29}$ In the standard case, we have the following parameter values: $\rho=0.4303, \frac{\tau^{P}}{w}=0.2, v=1, \sigma^{i}=1$, $i=P, F$ and $f\left(k_{t}\right)=k_{t}^{\gamma}$ where $\gamma=0.3$.

${ }^{30}$ It is actually possible to have $s^{F}-k(1+r)>0$. This is the case, for example, when $\rho=0$ and $\delta>0.87$. A time preference rate of zero is not very realistic, however. Therefore, we conclude that for realistic parameter values, it holds that $s^{F}-k(1+r)<0$.
} 


\section{Appendix B}

\section{B.1 Tax levied on the future old}

With government debt, linearizing the capital-accumulation equation (9) with respect to $\pi$ around the initial steady state gives:

$$
\frac{\partial s_{t}^{P}}{\partial \pi}+v \frac{\partial s_{t}^{F}}{\partial \pi}=(1+v) \frac{\partial k_{t+1}}{\partial \pi}+\frac{\partial b_{t+1}}{\partial \pi}
$$

From this, we can derive the following first-order difference equation for the change in the capital-labor ratio in case of different pension schemes:

$$
\begin{aligned}
\frac{\partial k_{t+1}^{P F}}{\partial \pi}= & \frac{\left[\frac{1}{\alpha^{P}}-1+v\left(\frac{1}{\alpha^{F}}-1\right)\right] k f^{\prime \prime}(k)}{\Delta} \frac{\partial k_{t}^{P F}}{\partial \pi}+\left(\frac{1}{\alpha^{P}}-1\right) \frac{\tau^{P} g_{t}}{\Delta} \\
& -\frac{1}{\alpha^{P} \Delta(1+r)}\left(\tau^{P} f_{t+1}-\frac{\partial \tau_{t+1}^{B}}{\partial \pi}\right)-\frac{1}{\Delta} \frac{\partial b_{t+1}^{P}}{\partial \pi}
\end{aligned}
$$

where $\Delta$ has the same definition as in Sect. 3.1. Comparing this equation with (12), we see that there are two extra terms, $\frac{\partial b_{t+1}^{P}}{\partial \pi}$ and $\frac{\partial \tau_{t+1}^{B}}{\partial \pi}$ because of the government debt created to compensate the old at $t=0$. As can be seen, debt has a direct negative impact on the change in the capital-labor ratio. However, because $\tau_{t}^{B}$ is levied on the pensioners, they will increase their savings when young which has a positive effect on the capital-labor ratio. Below, we show formally that savings increase exactly by the same amount as the government debt, so that the capital-labor stays constant with this pension reform scenario:

Proof Result 4 At $t=0$, we have that $\frac{\partial \tau_{0}^{P}}{\partial \pi}=\tau^{P} g_{0}, \frac{\partial z_{0}^{P}}{\partial \pi}=0$. Then using (4), we know that $\frac{\partial b_{1}^{P}}{\partial \pi}=-\frac{\partial \tau_{0}^{P}}{\partial \pi}=-\tau^{P} g_{0}$ and $\frac{\partial \tau_{1}^{B}}{\partial \pi}=r \frac{\partial b_{1}^{P}}{\partial \pi}$. So, that we can write $\frac{\partial k_{1}^{P F}}{\partial \pi}=$ $\left.\left(\frac{1}{\alpha^{P}}-1\right)\right) \frac{\tau^{P}}{\Delta} g_{0}-\frac{1}{\alpha^{P} \Delta(1+r)}\left(\tau^{P} f_{1}+r \tau^{P} g_{0}\right)+\frac{\tau^{P} g_{0}}{\Delta}$. Noting that $f_{1}=g_{0}$, it is easy to verify that $\frac{\partial k_{1}^{P F}}{\partial \pi}=0$. And when this is the case for $t=1$, this holds for all following periods.

\section{B.2 Tax levied on the future young}

In this case, the first-order difference equation for $k_{t}$ is:

$$
\begin{aligned}
\frac{\partial k_{t+1}^{P F}}{\partial \pi}= & \frac{\left[\frac{1}{\alpha^{P}}-1+v\left(\frac{1}{\alpha^{F}}-1\right)\right] k f^{\prime \prime}(k)}{\Delta} \frac{\partial k_{t}^{P F}}{\partial \pi}+\left(\frac{1}{\alpha^{P}}-1\right) \frac{\tau^{P} g_{t}+\frac{\partial \tau_{t}^{B}}{\partial \pi}}{\Delta} \\
& -\frac{1}{\alpha^{P} \Delta(1+r)} \tau^{P} f_{t+1}-\frac{1}{\Delta} \frac{\partial b_{t+1}^{P}}{\partial \pi}
\end{aligned}
$$

As can be seen this equation looks almost the same as (31), the only difference is that now $\tau_{t}^{B}$ has a negative impact on the change in the capital-labor ratio. 
Proof Result 5 The change in the capital-labor ratio at $t=1$ is $\frac{\partial k_{1}^{P F}}{\partial \pi}=\frac{\left(\frac{1}{\alpha^{P}}-1\right) \tau^{P}}{\Delta} g_{0}-$ $\frac{\tau^{P}}{\alpha^{P} \Delta(1+r)} f_{1}+\frac{1}{\Delta} \tau^{P} g_{0}$. This equation can be simplified to $\frac{\partial k_{1}^{P F}}{\partial \pi}=\frac{\tau^{P} r}{\Delta \alpha^{P}(1+r)} g_{0}<0$. So, we know that as soon $\tau_{t}^{B}$ is levied on the future young, the capital-labor ratio decreases at $t=1$.

\section{Appendix C}

Proof Result 7 Using (14), we know that the change in government debt at $t=1$ is equal to $\frac{\partial b_{1}^{P}}{\partial \pi}=-\left(1-2 \tau^{P}\right) \frac{\partial \tau_{0}^{P}}{\partial \pi}=-\left(1-2 \tau^{P}\right) \tau^{P} g_{0}$. Moreover, from $t=1$ onward, we have that $\frac{\partial z_{t}^{P}}{\partial \pi}=\left(1-2 \tau^{P}\right) \frac{\partial \tau_{t}^{P}}{\partial \pi}$, implying that $f_{1}=\left(1-2 \tau^{P}\right) g_{0}$, where we used the fact that $g_{1}=g_{0}$. Then noting that the capital-accumulation equation looks the same as (31) gives $\frac{\partial k_{1}^{P F}}{\partial \pi}=\left(\frac{1}{\alpha^{P}}-1\right) \frac{\tau^{P}}{\Delta} g_{0}-\frac{1}{\alpha^{P} \Delta(1+r)}\left[\left(1-2 \tau^{P}\right) \tau^{P} g_{0}+\right.$ $\left.r\left(1-2 \tau^{P}\right) \tau^{P} g_{0}\right]+\frac{1}{\Delta}\left(1-2 \tau^{P}\right) \tau^{P} g_{0}$, which can be written as $\frac{\partial k_{1}^{P F}}{\partial \pi}=\frac{2\left(\tau^{P}\right)^{2}\left(1-\alpha^{P}\right)}{\alpha^{P} \Delta} g_{0}$ $>0$.

\section{References}

Adema, Y., Meijdam, L., \& Verbon, H. A. A. (2008, forthcoming). Beggar thy thrifty neighbour: The international spillover effects of pensions under population ageing. Journal of Population Economics.

Belan, P., \& Pestieau, P. (1999). Privatizing social security: A critical assessment. Geneva Papers on Risk and Insurance Issues and Practice, 24(1), 114-130.

Belan, P., Michel, P., \& Pestieau, P. (1998). Pareto-improving social security reform. Geneva Papers on Risk and Insurance Theory, 23(2), 119-125.

Blundell, R., \& MaCurdy, T. (1999). Labor supply: a review of alternative approaches. In O. Ashenfelter \& D. Card (Eds.), Handbook of labor economics (Vol. 3A). Amsterdam: Elsevier. Chap. 27.

Boeri, T., Bovenberg, L., Coeuré, B., \& Roberts, A. (2006). Dealing with the new giants: Rethinking the role of pension funds. Geneva Reports on the World Economy, 8.

Börsch-Supan, A., Ludwig, A., \& Winter, J. (2006). Ageing, pension reform and capital flows: A multicountry simulation model. Economica, 73(292), 625-658.

Bovenberg, A. (2003). Financing retirement in the European Union. International Tax and Public Finance, $10,713-734$.

Bräuninger, M. (1999). Generalised social security finance in a two-country world. Scottish Journal of Political Economy, 46(3), 287-302.

Breyer, F. (1989). On the intergenerational Pareto efficiency of pay-as-you-go financed pension systems. Journal of Institutional and Theoretical Economics, 145, 643-658.

Breyer, F., \& Straub, M. (1993). Welfare effects of unfunded pension systems when labor supply is endogenous. Journal of Public Economics, 50(1), 77-91.

Brunner, J. (1996). Transition from a pay-as-you-go to a fully funded pension system: the case of differing individuals and intragenerational fairness. Journal of Public Economics, 60, 131-146.

Buiter, W. (1981). Time preference and international lending and borrowing in an overlapping-generations model. Journal of Political Economy, 89, 769-797.

Casamatta, G., Cremer, H., \& Pestieau, P. (2000). The political economy of social security. Scandinavian Journal of Economics, 102(3), 503-522.

Casarico, A. (2001). Pension systems in integrated capital markets. Topics in Economic Analysis \& Policy, 1(1), 1-17.

Cooley, T. F., \& Soares, J. (1999). Privatizing social security. Review of Economic Dynamics, 2(3), 731755. 
Diamond, P. (1965). National debt in a neoclassical growth model. American Economic Review, 55, 11261150.

Fehr, H., Jokisch, S., \& Kotlikoff, L. (2005). The developed worlds demographic transition-the role of capital flows, immigration, and policy. In R. Brooks \& A. Razin (Eds.), Social security reform (pp. 11-43). Cambridge: Cambridge University Press.

Feldstein, M. (2005). Structural reform of social security. Journal of Economic Perspectives, 19(2), $22-55$.

Fenge, R. (1995). Pareto efficiency of the pay-as-you-go pension system with intragenerational fairness. Finanzarchiv, 52, 357-363.

Fried, J., \& Howitt, P. (1988). Fiscal deficits, international trade and welfare. Journal of International Economics, 24.

Gale, D. (1973). Pure exchange equilibrium of dynamic economic models. Journal of Economic Theory, $6(1), 12-36$.

Homburg, S. (1990). The efficiency of unfunded pension schemes. Journal of Institutional and Theoretical Economics, 146, 640-647.

Homburg, S., \& Richter, W. F. (1993). Harmonizing public debt and public pension schemes in the European Community. Journal of Economics, Suppl. 7, 51-63.

INGENUE (2001). Macroeconomic consequences of pension reforms in Europe: An investigation with the INGENUE world model (Working Paper no. 2001-16).

Judd, K. (1982). An alternative to steady-state comparisons in perfect foresight models. Economics Letters, $10,55-59$.

Köthenbürger, M., \& Poutvaara, P. (2006). Social security reform and investment in education: Is there scope for a Pareto-improvement?. Economica, 73, 299-319.

Meijdam, L., \& Verhoeven, M. (1998). Comparative dynamics in perfect-foresight models. Computational Economics, 12, 115-124.

Pemberton, J. (2000). National and international privatisation of pensions. European Economic Review, 44(10), 1873-1896.

Perotti, R. (2001). Is a uniform social policy better? Fiscal federalism and factor mobility. The American Economic Review, 91(3), 596-610.

Persson, T. (1985). Deficits and intergenerational welfare in open economies. Journal of International Economics, 19(1-2), 67-84.

Pestieau, P., Piaser, G., \& Sato, M. (2006). PAYG pension systems with capital mobility. International Tax and Public Finance, 13, 587-599.

Samuelson, P. (1958). An exact consumption loan model of interest with or without the social contrivance of money. Journal of Political Economy, 66, 1002-1011.

Sinn, H. (2000). Why a funded pension system is useful and why it is not useful. International Tax and Public Finance, 7, 389-410.

Steigum, E., \& Raffelhüschen, B. (1994). Deficit spillovers, labor supply and intergenerational welfare (SNF-report no. 72/1994).

Verbon, H. (1989). Conversion policies for public pension plans in a small open economy. In B. Gustafsson \& N. Klevmarken (Eds.), The political economy of social security (pp. 83-95). Amsterdam: Elsevier Science. 